\title{
Reforma Cabanis (Circa 1800): uma reforma universitária sem universidades, esquecida na história da educação
}

\author{
Naomar Almeida-Filho
}

Resumo:

Proponho designar como Reforma Cabanis o conjunto de políticas, normas e iniciativas de reforma do ensino médico que, após a Revolução Francesa, resultaram em modelos de ensino superior orientados ao profissionalismo, à disciplinaridade e à especialização. Neste ensaio, apresento a Reforma Cabanis em mais detalhe, avaliando contextos, estrutura e natureza de suas propostas, buscando compreender porque essa reforma universitária parece ter sido esquecida na história da educação. Na primeira parte, faço breve análise do processo de reestruturação do sistema de educação da França pós-revolucionária, destacando aspectos históricos e político-institucionais da contribuição de Cabanis. Na segunda parte, apresento os elementos principais dessa proposta de reorganização institucional e político-pedagógica do ensino médico que catalisou a criação de um novo modelo de educação superior, onde a universidade tem existência apenas nominal. $\mathrm{Na}$ parte conclusiva, indico que, ao instituir o ensino superior baseado em faculdades, profissões, disciplinas e especialidades, com exclusão do conceito de Universidade como formato secular de instituição de formação geral, a Reforma Cabanis configurou um modelo de educação que, orgânico ao capitalismo pós-colonial, tornou-se hegemônico no espaço cultural latino-americano.

Palavras-chave:

Cabanis; revolução francesa; reforma universitária; educação superior 


\title{
Cabanis Reform (circa 1800): A university reform without universities, forgotten in the history of education.
}

\begin{abstract}
I propose to name as Cabanis Reform a set of policies, laws and initiatives of educational reform that, after the French Revolution, lead to higher education models oriented towards professionalism, disciplinarity and specialization. In this essay, I introduce the Cabanis Reform in more detail, evaluating contexts, structure and nature of its proposals, seeking to understand why this academic reform seems to have been forgotten in the history of education. In the first part, I briefly analyse the process of restructuring the educational system of post-revolutionary France, highlighting historical and politico-institutional dimensions of Cabanis' contribution. In the second part, I present the main elements of this proposal of institutional and politico-educational reform of medical training that catalysed the creation of a new model of higher education, where the university has only a nominal existence. In conclusion, I suggest that, by instituting higher education based on faculties, professions, disciplines and specialties, excluding the concept of the University as a secular format of general education institution, Cabanis Reform has configured a model of education organic to postcolonial capitalism, which has become hegemonic in the Latin American cultural space.
\end{abstract}

Keywords: Cabanis; french revolution; university reform; higher education

\section{La Réforme Cabanis (circa 1800): Une réforme universitaire sans universités, oubliée dans l'histoire de l'éducation.}

Résumé: Je propose de désigner comme la Réforme Cabanis l'ensemble des politiques, des normes et des initiatives de réforme de l'éducation médicale qui, après la Révolution Française, aboutissent à des modèles d'enseignement orientés vers le professionnalisme, la disciplinarité et la spécialisation. Dans cet essai, je présente la Réforme Cabanis plus en détail, en évaluant les contextes, la structure et la nature de ses propositions, cherchant à comprendre pourquoi cette réforme universitaire semble avoir été oubliée dans I'histoire de l'éducation. Dans la première partie du texte, je fais une brève analyse du processus de restructuration du système éducatif de la France postrévolutionnaire, en mettant en évidence les aspects historiques et politico-institutionnels de la contribution de Cabanis. Dans la deuxième partie, je présente les principaux éléments de cette proposition de réorganisation institutionnelle et politico pédagogique de l'éducation médicale qui a catalysé la création d’un nouveau modèle de l,enseignement supérieur, où l'université n'a qu'une existence nominale. Dans la conclusion, je souligne que, en instituant l'enseignement supérieur basé sur les facultés, professions, disciplines et spécialités, avec l'exclusion du concept d'université comme forme laïque d'institution de formation générale, la Réforme Cabanis a configuré un modèle d'enseignement supérieur, organique au capitalisme postcolonial, qui est devenu hégémonique dans l'espace culturel latino-américain.

Mots-clés: Cabanis; révolution française; réforme universitaire; enseignement supérieur

\section{La Reforma Cabanis (circa 1800): Una reforma universitária sin universidades, olvidada en la história de la educación.}

Resumen: Propongo designar como Reforma Cabanis al conjunto de políticas, normas e iniciativas de reforma de la enseñanza médica que, tras la Revolución Francesa, resultaron en modelos de educación superior orientados hacia el profesionalismo, la disciplinaridad y la especialización. En este ensayo, presento la Reforma Cabanis en más detalle, evaluando contextos, estructura y naturaleza de sus propuestas, buscando comprender porque esa reforma universitária parece ter sido olvidada en la história de la educación. En la primera parte, hago breve análisis del proceso de reestructuración del sistema de educación de Francia post-revolucionaria, destacando aspectos históricos y político-institucionales de la contribución de Cabanis. En la segunda parte, presento los elementos principales de esa propuesta de reorganización institucional y político-pedagógica de la enseñanza médica que catalizó la creación de un nuevo modelo de educación superior, donde la universidad tiene existencia solamente nominal. En la parte conclusiva, indico que, al instituir la enseñanza superior basada en facultades, profesiones, disciplinas y especialidades, con exclusión del concepto de Universidad como formato secular de institución de formación general, la Reforma Cabanis configuró un modelo de educación que, orgánico al capitalismo poscolonial, se hizo hegemónico en el espacio cultural latinoamericano.

Palabras clave: Cabanis; revolución francesa; reforma universitaria; educación superior 


\section{Introdução}

Entre os séculos XVII e XIX, consolidou-se na Europa ocidental um modelo de educação superior vocacional onde a instituição universitária, fortemente impregnada pelo poder do clero, tornara-se conservadora e resistia àquele momento histórico de explosão do conhecimento científico. Nesse cenário de profundas mudanças econômicas e políticas, com a emergência de um novo modo de produção, ascensão de classes sociais antes subalternas e configuração de novas formas de governo, a já secular instituição de conhecimento chamada Universidade passou a enfrentar sérias crises de identidade e finalidade social (Charle \& Verger, 2012). A Reforma Humboldt, solução germânica para superar essas crises, de certa forma facilitada pela descentralização religiosa herdada do cisma luterano, implicou retomada ativa de princípios originais da Universidade como dispositivo civilizatório (pelo menos do ponto de vista do capitalismo eurocêntrico) e conceito político estratégico para unificação da nação alemã (Backhaus, 2015). Com o modelo de research university, materializado na Universidade de Berlim em 1810, a articulação entre ensino e produção de ciência se tornou o elemento definidor das instituições universitárias na Europa setentrional. Um século mais tarde, o modelo humboldtiano foi atualizado e adotado nas universidades norte-americanas através da Reforma Flexner, tornando-se hegemônico nos países de cultura anglo-saxã (Sousa-Santos \& Almeida-Filho, 2008).

Momento de grande turbulência política e rápida transformação social, a Revolução Francesa de 1789 produziu uma solução radical para a crise da universidade: suprimiu as universidades. Reconhecidas como organismo elitista de formação de quadros para o estado-nação absolutista e denunciadas como nichos do diletantismo aristocrático, as universidades francesas foram simplesmente extintas e suas funções assumidas por outros tipos de instituição de ensino superior (Charle \& Verger, 1996). Entre 1790 e 1800 , várias estratégias e soluções, sintetizadas em diferentes propostas e documentos, concretizaram-se primeiro na reorganização do ensino médico e estenderam-se posteriormente a outros campos de formação profissional e acadêmica, no contexto de reestruturação geral do sistema educacional da França pós-revolucionária. Considerando a ativa participação de Pierre-Jean Georges Cabanis ${ }^{1}$ nesse processo, propus designar como Reforma Cabanis o conjunto de políticas, normas e iniciativas de reforma do ensino médico que resultaram em modelos de ensino superior baseados em faculdades e orientados ao profissionalismo, à disciplinaridade e à especialização (Almeida-Filho, 2017).

Neste ensaio, apresento a Reforma Cabanis em mais detalhe, avaliando contextos, estrutura e natureza de suas propostas, buscando compreender porque essa reforma universitária parece ter sido esquecida na história da educação. Na primeira parte, faço breve análise do processo de reestruturação do sistema de educação da 
França pós-revolucionária, destacando aspectos históricos e político-institucionais da contribuição de Cabanis. Na segunda parte, apresento os elementos principais dessa proposta de reorganização institucional e político-pedagógica do ensino médico que catalisou a criação de um novo modelo de educação superior, onde a universidade tem existência apenas nominal. Na parte conclusiva, indico que, ao instituir o ensino superior baseado em faculdades, profissões, disciplinas e especialidades, com exclusão do conceito de Universidade como formato secular de instituição de formação geral, a Reforma Cabanis configurou um modelo de educação que, orgânico ao capitalismo pós-colonial, tornou-se hegemônico no espaço cultural latino-americano.

\section{Mirabeau, Condorcet, Cabanis: Reforma da Educação}

Nos momentos iniciais da Revolução de 1789, duas medidas radicais redefiniram os rumos da educação: o fim do monopólio religioso no cenário educacional e a supressão sumária de universidades e academias (Barnard, 1969). Em 1790, a Convenção Nacional nomeou um Comité d'instruction publique, a fim de coordenar a reordenação da educação na França, tendo como prioridade política reduzir ao máximo a influência religiosa na formação dos cidadãos (Verneuil, 2013). Em vez de instituições de ensino promotoras de pensamento filosófico doutrinário, saberes abstratos e cultura erudita, a serviço de uma aristocracia diletante e alienada, a nascente República precisaria mais de uma rede eficiente de órgãos públicos para formação política, técnica e profissional de cidadãos livres. Muitos aspectos de uma nova configuração do sistema educacional eram objeto de preocupação geral, incluindo deveres e prerrogativas do Estado, situação econômica da nação, necessidades e especificidades do ensino superior, urgência em se formar professores e condições da profissão docente no novo regime.

Nenhum desses temas era estranho ao jovem revolucionário Cabanis, mesmo porque formavam a base dos discursos de Mirabeau sobre educação, por ele reunidos, após a morte precoce do tribuno, numa publicação intitulada Travail sur l'Éducation publique. Para vários autores (Pouliquen, 2013; Saad, 2014), o próprio Cabanis teria sido autor dos textos do Travail. Essa hipótese se aplica sobretudo ao primeiro discurso, que propunha um modelo hierarquizado de instrução pública e justificava uma nova estrutura de ensino superior sem universidades. A formação em todas as profissões civis e militares seria realizada por écoles spéciales, com plena autonomia administrativa e financeira. Reforçando a hipótese de que, de fato, trata-se mais de uma proposta do jovem médico do que efetivamente do brilhante tribuno, vários pontos desse documento nos autorizam, por justiça, a citá-lo como Plano Mirabeau-Cabanis. No texto do discurso, sete das 35 páginas abordam o ensino médico; a minuta de decreto legislativo compreende 29 artigos sobre faculdades de medicina (quatro a mais que o 
pertinente a todas as outras formações!), culminando com a proposta de abertura de escolas médicas em todos os departamentos da República Francesa. O próprio autor (Mirabeau/Cabanis, 1791, p.26) reconhece que as propostas relativas ao ensino médico mostram-se desproporcionais: Vós não sereis então surpreendidos, Senhores, [ao ver] que a Medicina ocupa um lugar considerável no meu plano de instrução pública.

Em seguimento, o Marquês de Condorcet, membro do Comité d'instruction publique, apresentou uma plataforma para a reforma educacional da Revolução, em dois momentos. No primeiro, publicou cinco memórias de cunho filosófico e político-pedagógico (Condorcet, 1791). As primeiras memórias arrolavam razões filosóficas e políticas para a igualdade na educação e estabeleciam as bases da instrução comum a todas as crianças, pertinente ao repertório cognitivo mínimo para prosseguir sua formação aos níveis seguintes. A terceira memória dizia respeito à instrução necessária para a emancipação política, enquanto a quarta memória tratava da educação para carreiras profissionais necessárias à república. Finalmente, a mais filosófica dessas memórias propunha que todo o conhecimento científico fosse inter-relacionado e que, para isso, seria pertinente criar institutos exclusivos para formação de professores e cientistas.

No segundo momento, Condorcet (1792) apresentou à Assembleia Nacional um ambicioso plano de criação de uma rede pública destinada a prover educação em todos os níveis, com a seguinte estrutura hierárquica: (a) uma école primaire para cada vila ou bairro com até 1.500 habitantes; (b) uma école sécondaire para cada vila ou bairro com até 6.000 habitantes; (c) em todo o país, 140 instituts, destinados ao ensino básico e aplicado de ciências matemáticas e físicas, ciências morais e políticas, ciências aplicadas e literatura e belas-artes; (d) nove lycées, um em cada região do país, especializados no ensino superior inicial nas áreas científicas e artísticas; e) uma société nationale des sciences et arts, para supervisão e coordenação central dos liceus e institutos. O Plano Condorcet incluía minuciosa minuta de decreto legislativo, com proposta orçamentária e estudo de viabilidade. Esse grau de detalhamento demonstra que se tratava de construção coletiva, tendo contribuições reconhecidas de Garat e Cabanis. Mesmo apresentado em nome do Comité, com amplo apoio de influentes intelectuais, o projeto foi rejeitado pela Assembleia.

Com a superação da turbulência política do Terror, que infelizmente custou a vida de Condorcet, o governo revolucionário pôde enfim alcançar maior estabilidade institucional e priorizar a reforma educacional. François Daunou, um dos mais ativos membros do Comité d'Instruction publique, redigiu um projeto de lei da educação pública, submetida à Convenção no final de 1795 e logo aprovada. Recuperando parcialmente tanto a proposta Mirabeau-Cabanis quanto o projeto de Condorcet, essa lei estabelecia a formação de professores como principal prioridade nacional, criando a École normale de Paris, com base num currículo que incluía "a moral republicana e as virtudes públicas 
e privadas". Por outro lado, distanciando-se do Plano Condorcet, foi implantado um modelo centralizado de educação parcialmente pública, com abertura de écoles centrales de ensino médio, sendo um estabelecimento para cada 300.000 pessoas, incluindo biblioteca, jardim botânico e museu de história natural (Barnard, 1969).

Apesar desse esforço, a qualidade da educação pública na França pós-revolucionária continuava precária e a situação do ensino cada vez mais preocupante, evidenciando o fracasso de uma política educacional focal e centralizadora. Algumas escolas, localizadas nos principais centros urbanos, conseguiam ministrar ensino de qualidade, contrastando com o resto do país, onde a situação continuava caótica. As escolas de ensino fundamental continuavam fora da gestão do Estado, muitas delas em mãos de ordens religiosas e sem professores treinados nas diretrizes científicas, políticas e sociais da República (Barnard, 1969).

\section{Cenário da Reforma Cabanis}

Na França do final do século XVIII, abundavam escolas médicas de baixa qualidade, onde as cátedras eram cargos disputados pela nobreza decadente como fonte de renda já que somente catedráticos eram autorizados a ministrar cursos pagos (Brockliss, 1998). A formação prática se fazia fora dos espaços acadêmicos formais, pois os aprendizes de médico precisavam seguir, em visitas domiciliares, "um médico renomado a quem é preciso indenizar" e, além disso, pagavam caro pela preparação dos exames de qualificação; tudo isso inflacionava os custos da educação médica (Foucault, 2011, p.48). ${ }^{2}$

Entre 1790 e 1793, Félix Vicq d'Azyr e Antoine de Fourcroy, ambos médicos e políticos, encaminharam várias propostas de reestruturação do ensino médico, numa perspectiva integradora da formação médica, com unificação definitiva do ensino de Medicina, Cirurgia e Farmácia num único diploma universitário, formação anátomo-clínica, superando a instrução retórica por uma didática baseada na prática laboratorial, e extinção de faculdades de medicina, substituindo-as por écoles de santé (Foucault, 2011, p.76). Acolhido com entusiasmo pelos próceres da Revolução, o Plano d'Azyr-Fourcroy foi aprovado pela Assembleia em fevereiro de 1794, ampliado para mais duas escolas de saúde nas províncias (Rosen, 1946). Cabanis apoiou alguns pontos da proposta, porém mostrava-se cético em relação ao fechamento das faculdades e discordava da importância concedida ao ensino de Farmacoquímica como base do novo currículo.

A pioneira École de Paris foi instalada no prédio onde funcionava a academia médico-cirúrgica, desapropriado pela Revolução (Rey, 1993). Havia três classes de alunos regulares (officiers de santé, chirurgiens, médecins), além de alunos ouvintes (auditeurs libres). A classe de cada estudante se definia mediante exames públicos. A duração 
da formação variava: officier de santé, três anos; chirurgien, quatro anos, médecin, cinco anos. Para os que pretendiam seguir a carreira médica, além da aprovação nos exames, era preciso elaborar e defender uma Thèse de Doctorat en Médécine. Uma análise de conteúdo das teses defendidas na École de Santé de Paris, no apogeu do seu monopólio como principal polo de formação de profissionais de saúde em todo o território francês, revela sofisticado grau de integração epistemológica (Rey, 1993, p. 39).

Na prática, o Plano d'Azyr-Fourcroy sofreu recuos estratégicos que terminaram por inviabilizá-lo, principalmente devido à ascensão de um modelo de corporação profissional organicamente articulado com a rede política republicana. O consenso político e social alcançado pela solução conservadora fomentou então modelos de educação superior com viés vocacional, capazes de responder às demandas imediatas da conjuntura econômica, orgânicos à mentalidade religiosa restaurada e, ao mesmo tempo, congruentes com a nascente ideologia burguesa individualista, produtivista e laica (Foucault, 2011). Essa falência pode ser explicada por três motivos (Foucault, 2011): a desregulamentação dos primeiros anos da Revolução teria produzido respostas sociais abusivas, com auto-designação de muitos profissionais desqualificados, mesmo charlatães; a partir do Thermidor, agremiações profissionais ressurgiram com força e pressionavam para retomar seus antigos papéis corporativos; academias e sociedades científicas retomaram protagonismo político e passaram a lutar pela reabertura de escolas e faculdades. Em 1797, a Societé de santé de Paris, fundada pelos médicos que formavam o corpo docente das escolas de saúde, foi renomeada como Societé de médecine de Paris. Na virada do século XIX, já no contexto bonapartista, todas as instituições de ensino médico haviam abandonado a denominação école de santé assumindo a designação mais tradicional de Faculté (ou école) de médecine (Williams, 1994, p.72).

Nesse contexto, em 1796, Desttut de Tracy tornou-se secretário geral do Comité d'Instruction publique, convidando Cabanis como colaborador; juntos, começavam a articular o agrupamento de intelectuais que se tornaria conhecido como Les idéologues (Williams, 1994). Antecipando em quase dois séculos a noção contemporânea de "democracia cognitiva", os ideólogos defendiam que somente haveria progresso social com igualdade intelectual para todos os seres humanos, mediante acesso amplo ao conhecimento através de uma educação libertadora. Essa nova política, por sua vez, exigiria uma nova ciência e uma nova pedagogia, ambas fundadas numa epistemologia revolucionária, uma verdadeira "ciência dos métodos". Essa metaciência, a ser fundada, envolveria uma lógica dos modos de pensamento, uma idéologie ${ }^{3}$ e uma fisiologia dos sistemas psíquicos, com uma abordagem original da questão cartesiana da relação corpo-mente, contribuição do próprio Cabanis (Staum, 1980). 
Em convergência com Mirabeau e Condorcet, Cabanis considerava a instrução pública crucial numa república moderna fundada nos princípios da liberdade e da igualdade, na medida em que o sistema democrático dependia de que todos os cidadãos tivessem plena capacidade para participar dos processos deliberativos, da avaliação de dirigentes e do julgamento da representatividade política (Saad, 2016). Nessa perspectiva, propunha mitigar os efeitos da iniquidade física e moral, promovendo o que definiu como "igualdade de meios" mediante três planos de intervenção: política - garantindo igualdade de direitos; médica - para reduzir as desigualdades físicas e mentais inatas; educacional - para gerar igualdade de oportunidades sociais.

\section{A Reforma Cabanis}

Confirmada a insustentabilidade política do Plano d'Azyr-Fourcroy, abriu-se espaço para o ressurgimento de faculdades, reforçadas por academias e corporações empoderadas, sem o controle central de universidades. Aproveitando sua posição política no Conselho dos Quinhentos, além de colaborador no Comité d'instruction publique, Cabanis veio a se confirmar como importante quadro intelectual nesse processo. Assim, sob sua liderança, registra-se a proposição e aprovação de um conjunto de diretrizes, normas e medidas que, com certo distanciamento histórico, justifica chamarmos de Reforma Cabanis.

Como conjunto propositivo, etapa inicial para uma reforma do ensino superior com viabilidade política na conjuntura pós-revolucionária, a Reforma Cabanis compreende cinco elementos estruturais:

1. função social mais profissionalista do que científica ou cultural;

2. modelo organizacional estruturado em faculdades;

3. formação hospitalocêntrica de base intervencionista;

4. currículos orientados à disciplinaridade, em regime de progressão linear;

5. estratégia pedagógica analítica, tendente ao especialismo.

Vejamos cada um destes pontos:

1 - Inicialmente focalizando na prática médica, a Reforma Cabanis introduziu o conceito oficial de "licenciatura" (license), dispositivo legalmente habilitador ao exercício profissional. O licenciamento da prática médico-cirúrgica, mediante certificação outorgada por instituição de ensino superior credenciada, permitiria, diretamente ou através de mecanismos de mediação (como exames periódicos de competência), maior controle do Estado sobre uma esfera da vida civil crucial para proteção da saúde das pessoas. Nesse modelo de articulação educação-sociedade, a instituição de ensino superior tem responsabilidade de emitir diplomas ou certificados que, formalmente, são reconhecidos como válidos e, portanto, autorizam a prática profissional. O caráter de instrumento regulatório do diploma médico se estendeu rapidamente a outras 
profissões que implicavam, por um lado, responsabilidade civil e relevância social e, por outro lado, acesso a mercados de trabalho de impacto econômico prioritário e maior acumulação de capital político.

2 - No modelo cabanisiano, o ensino superior deveria ser realizado em faculdades independentes, com maior grau de autonomia perante o Estado regulador e a instituição universitário, tanto nos aspectos pedagógicos quanto na condução das atividades de formação. As faculdades seriam organizadas no regime de cátedra, definida como a unidade produtiva da instrução capaz de ser gerida acadêmica e administrativamente por uma única liderança intelectual que dominaria todo o conhecimento sobre aquela matéria, o catedrático. O perfil de competências profissionais definido nesse modelo configurava uma prática orientada por conhecimentos científicos naturalistas; no caso do ensino médico, uma prática diagnóstica de base semiológica, confirmada por respostas terapêuticas e correlações anátomo-clínicas.

3 - Para modernizar o modelo de formação, seria necessário redefinir espaços de aprendizagem adequados às novas práticas profissionais; no caso da saúde, prática clínica em instituições de cuidado em saúde, fundada em conhecimento nosológico sistemático. Assim, a partir do processo de laicização dos hospitais, em vez da relação mestre-aprendiz, própria da formação clínica praticamente artesanal propiciada pelo acompanhamento de médicos particulares em visitas domiciliares, a Reforma Cabanis tornaria obrigatória a instrução profissional em internato (internat des hôpitaux) que depois evoluiu para o conceito moderno de residência médica. Não obstante, o ensino das disciplinas básicas e da matéria médica continuaria sendo realizado em anfiteatros e salas de aula organizados de acordo com as cátedras respectivas.

4 - Propunha-se uma nova estrutura curricular baseada no conceito de disciplina. Na dimensão cognitiva, onde o conhecimento seria decomposto em suas partes constitutivas, as disciplinas equivaleriam às cátedras, na dimensão organizativa institucional. Nesse sentido, a disciplina compreendia o conjunto de saberes e conhecimentos de acesso restrito aos discipuli de um magister - o catedrático. No caso do conhecimento médico, foco original da Reforma Cabanis, as disciplinas deveriam ser diferenciadas com precisão e, para efeito de estrutura curricular, agrupadas em história natural (ciências básicas), matéria médica (ciências clínicas e terapêuticas) e ciências morais. A principal consequência desse modelo de organização curricular disciplinar sobre os modos de cuidado em saúde foi a fragmentação da prática (inicialmente cirúrgica e depois clínica) em especialidades médicas.

5 - A Reforma Cabanis implicava uma estratégia pedagógica inovadora, denominada método analítico de ensino, equivalente à análise racional dos ideólogos. O conhecimento científico seria validado se decomposto e sintetizado pela ordem linear cartesiana, da matéria mais simples à mais complexa, numa operação de exaustividade metódica. Assim, a pedagogia analítica baseada na disciplinaridade corresponderia 
à fragmentação, análise e posterior ordenação de blocos de conteúdos, modos de prática e, principalmente, conhecimentos, memorizados, codificados e classificados segundo as doutrinas científicas vigentes. Conforme preconizado nos discursos do Travail, isso exigiria a superação da retórica como modelo pedagógico, com o consequente abandono do Latim como cripto-linguagem técnica, codificada como elemento de diferenciação e elitização da corporação profissional. Com isso, formar-se-ia um novo tipo de médico, capacitado a se relacionar com seus pacientes de modo menos hierarquizado e distante.

O Coup d'oeil sur les Revolutions et Réforme de la Médecine (Cabanis, 1804) pode ser reconhecido como o manifesto histórico-político-pedagógico da Reforma Cabanis. Configurada como um estudo de história da medicina, essa obra estabelece as bases de um novo currículo e uma nova pedagogia necessários para a reforma do ensino médico, por sua vez imprescindível para a sustentabilidade da revolução iniciada nos sistemas de saúde da França, no limiar da modernidade. Por tudo isso, diferentemente de Foucault, Rosen (1946, p.337) concede máximo valor ao Coup d'oeil, reconhecendo-o como marco intelectual da reinvenção cultural da medicina:

Este trabalho é ao mesmo tempo uma história da medicina e um programa para a reforma da educação médica. Embora as ideias apresentadas neste livro não postulem [explicitamente] a restauração das escolas de medicina, elas de fato refletem a filosofia básica da instrução dada aos estudantes da Faculdade de Medicina de Paris.

Nas dimensões conceitual e político-pedagógica, a Reforma Cabanis exibia com clareza sua linhagem intelectual, manifesta como propostas concretas em várias etapas de revolução da medicina e reforma do ensino médico. Do ponto de vista conceitual, mostrava-se, desde o início, delimitada pelas filosofias naturalistas do lluminismo e pelas biociências emergentes. Cabanis articula a filosofia sensualista ao vitalismo neo-hipocrático, formulando uma teoria semiótica que integra fisiologia, anatomia, patologia e terapêutica, propondo que a dinâmica saúde-doença seria melhor interpretada como uma linguagem (Saad, 2016). Do ponto de vista pedagógico, o projeto da Reforma Cabanis se institui na interface entre a clínica, a política e a didática, implicando igualmente uma mudança crítica, rejeitando estratégias retóricas de formação no campo da saúde, substituindo o discurso de autoridade por maior ênfase na prática baseada na experimentação.

Assim, a Reforma Cabanis buscava incorporar propostas parciais, de natureza conjuntural, simultaneamente carregando claro sentido prático e forte viés político. Articulava, de modo preciso, objetivo e criativo, diversos movimentos de reforma da instrução pública e de organização do cuidado à saúde que haviam sido propostos no 
período pós-revolucionário. Com Mirabeau, pretendia resgatar as academias e sociedades científicas proscritas pela Revolução, bem como superar a universidade como conceito e organismo coordenador, propondo uma estrutura institucional descentralizada, baseada em faculdades e escolas isoladas. Do Plano Condorcet, defendia uma rede pública de educação, com acesso universal, composta, na esfera da educação superior, por órgãos isolados e especializados de formação profissional. Do Plano d'Azyr-Fourcroy, incorporou sem dificuldades a proposta de tripla condensação entre Medicina-Cirurgia-Farmácia, além dos elementos de Filosofia Moral necessários à formação cidadã politicamente engajada do novo perfil de médico, importantes naquele momento para reforçar a pauta política da revolução burguesa.

\section{Comentários Finais}

No complexo processo de regeneração institucional do Estado, do regime jurídico, do modo de cuidado em saúde e do sistema de educação após a Revolução de 1789, a Reforma Cabanis propiciou emergência e consolidação, na esfera da educação superior, do regime linear de formação profissional. Nesse regime, a instrução tem como base escolas ou institutos isolados; a pessoa não se forma na universidade, e sim numa faculdade, sob a hegemonia de uma dada profissão legitimada pelo Estado. No modelo cabanisiano de educação superior, portanto, não havia lugar para o conceito de Universidade 4 enquanto formato secular de instituição de formação geral, propiciadora de uma iniciação de sujeitos na cultura dominante.

Com esse modelo institucional, consolidava-se uma arquitetura curricular para formação exclusiva em carreiras profissionais mediante ensino superior cada vez mais disciplinar e especializado. Para compreensão desse processo, uma primeira hipótese vê a origem da especialização profissional na especialização acadêmica resultante da diferenciação e subdivisões entre disciplinas científicas da Reforma Humboldt na universidade prussiana (Habinek, 2010). Com a difusão internacional do modelo da universidade de pesquisa, a especiação disciplinar das ciências teria se estendido à estrutura curricular do ensino e, posteriormente, à organização das práticas profissionais. Weisz (2006) propõe uma hipótese distinta: a especialização teria se iniciado no campo profissional da saúde, no processo de acomodação entre cirurgia, clínica, farmácia e medicina veterinária, com a conformação de espaços de competição profissional entre 1830 e 1850. Nessa hipótese, a dupla reforma (tanto prática quanto pedagógica) protagonizada por Cabanis pode ser ressaltada como movimento crucial de articulação entre uma estrutura epistemológica fundada em disciplinas científicas básicas para a formação médica num contexto de profissionalismo, disciplinaridade e especialização.

Em outras palavras, a Reforma Cabanis teria sido também indutora da tendência à divisão-diferenciação de especialidades, que se tornaria um reconhecido demarcador 
do modo de cuidado à saúde predominante no século XX. A principal consequência desse processo, pelo menos na esfera de influência do modelo francês de educação, foi a hegemonia de uma formação disciplinar fragmentada e linear numa universidade que, antes uma casa das ciências, das artes e da cultura, tornara-se promotora de formação técnica e profissional especializada, reduzida a uma instituição vocacional, orgânica ao modo de produção fundado na produção industrial massificada.

Note-se que, em princípio, a Reforma Cabanis se restringia ao ensino médico, porém, dado o enorme capital político acumulado pela atuação de médicos-políticos- gestores na queda do Ancien Régime, efetivamente foi catalisadora de uma recriação do sistema educacional francês. Tal constatação não se aplica apenas à conjuntura pós-Revolução Francesa. Um século mais tarde, no início do século XX, uma reforma setorial do ensino médico - a Reforma Flexner, destinada a completar o ciclo iniciado pela Reforma Humboldt (contemporânea à Reforma Cabanis) - terminaria provocando ampla renovação no sistema universitário norte-americano (Almeida-Filho, 2010), tornando-o padrão de excelência acadêmica no mundo contemporâneo. O fato de uma transformação tópica ter conseguido se tornar ruptura generalizada, acolhida até pelos movimentos que a ela se opunham, certamente deve-se ao que Foucault posteriormente chamaria de biopolítica, numa de suas mais potentes modalidades regionais: o poder médico (Foucault, 2008). Mais uma vez, constata-se a centralidade das práticas de cuidado na constituição das sociedades modernas, na medida em que uma reforma setorial do ensino médico provocou profundas transformações na educação superior em geral, com reconfiguração de todo o sistema educacional.

Enfim, em algumas formações sociais derivadas do capitalismo mercantil pós-coIonial, a Reforma Cabanis gerou um modelo de ensino superior baseado em unidades dotadas de autonomia para decidir de modo independente sobre normas, disciplinas e cursos - as faculdades, deslocando a universidade como principal instituição educacional da modernidade. Incorporado à reforma educacional bonapartista, no início do século XIX, esse modelo de ensino superior tornou-se paradigmático para outros povos submetidos à poderosa influência cultural francesa, principalmente em países da Europa meridional e suas ex-colônias, como Brasil, Argentina e outras nações da America Latina.

\section{NOTAS:}

1 - Cabanis [1757-1808] foi um médico francês que, na virada do Século XIX, alcançou grande reputação como pesquisador, filósofo e líder político. Participou ativamente da Revolução Francesa, apresentando uma série de rapports sobre instrução pública, hospitais, ensino médico e assistência social que muito influenciaram as medidas de reestruturação institucional do novo regime. Durante o Terror, foi perseguido e sofreu com a prisão e morte de amigos próximos; com o fim do Terror em 1794, retomou intensa atividade política e organizou, junto com Destutt de Tracy, o movimento intelectual que a posteridade chamaria de Idéologie. Membro do Institut Nacional de France, órgão de política científica e educacional da Revolução, formulou um conjunto de observações, reflexões políticas e filosóficas, além de propostas curriculares e pedagógicas para a escola médica ideal. Com a reabertura das faculdades em 1797, implantou um novo modelo de 
ensino clínico na Faculdade de Medicina de Paris. Eleito para o Conselho dos Quinhentos, participou ativamente do golpe de Estado do 18 Brumário, que deu início à era napoleônica. Político habilidoso e bem relacionado, conseguiu, não sem dificuldades, aprovar a maior parte de sua agenda. Em 1799, foi nomeado para a cátedra de História da Medicina da Faculdade de Medicina de Paris. Em protesto contra o autoritarismo e belicismo do governo bonapartista, retirou-se da vida pública a partir de 1800. Antes de falecer em 1808, escreveu Rapports du physique et du moral de l'homme, uma teoria fisiológica do conhecimento objeto de grande polêmica (Cabanis, 1802), e organizou seus escritos sobre reforma da educação médica num livro-testamento, intitulado Coup d'oeil sur révolutions et réforme de la médecine (Cabanis, 1804).

2 - Essa descrição crítica do cenário do ensino médico na França, no fim do século XVIII, parece muito com o contexto norte-americano estudado por Abraham Flexner, e desconstruído pela reforma que levou seu nome, na segunda década do Século XX (Almeida Filho, 2010).

3 - Num pequeno texto que se tornou clássico, intitulado Ideologia e Aparelhos Ideológicos de Estado, Louis Althusser (1976, p.36) atribui a primazia pela formulação do conceito de 'idéologie' primeiro a Cabanis e, somente depois, a Destutt de Tracy e seus companheiros ideólogos.

4 - No Coup d'oeil, por exemplo, o termo 'universidade' tem apenas cinco ocorrências, todas referidas à história da medicina em épocas remotas.

\section{Referências Bibliográficas}

Almeida-Filho, N. (2010). Reconhecer Flexner: inquérito sobre produção de mitos na educação médica no Brasil contemporâneo. Cadernos de Saúde Pública, 26, 2234-2249.

Almeida-Filho, N. (2017). O legado de Cabanis: hipótese sobre raízes da educação médica no Brasil. Cadernos de Saúde Pública, 33, Epub. e00206416.

Althusser, L. (1976). Idéologie et appareils idéologiques d’État. In: Althusser, Louis. Positions (pp.67125). Paris: Les Éditions Sociales.

Backhaus, J. (ed.) (2015). The University According to Humboldt: History, Policy, and Future Possibilities. Berlin: Springer.

Barnard, H. (1969). Education and the French Revolution. Cambridge: Cambridge University Press.

Brockliss, L. (1998). Before the Clinic: French Medical Teaching in the Eighteenth Century. In: Caroline Hannaway and Ann La Berge. Constructing Paris Medicine (pp.71-115). Amsterdam: Rodopi Editions.

Cabanis, P-J-G. (1802). Rapports du physique et du moral de l'homme. http://gallica.bnf.fr/ark:/12148/ bpt6k77029t.r=cabanis.langFR

Cabanis, P-J-G. (1804). Coup d'oeil sur les Revolutions et Réforme de la Médecine. http://gallica.bnf.fr/ ark:/12148/bpt6k76544v/f6.image

Charle, C., Verger, J. (2012). Histoire des universités. Paris: PUF.

Condorcet, N-C. (1791). Cinq mémoires sur l'instruction publique. http://classiques.uqac.ca/classiques/ condorcet/cinq_memoires_instruction/Cinq_memoires_instr_pub.pdf

Condorcet, N-C. (1792). Rapport et projet de décret sur l'organisation générale de l'instruction publique. http://gallica.bnf.fr/ark:/12148/bpt6k488703

Foucault, M. (2008). Nascimento da Biopolítica: curso dado no Collège de France (1978-1979). São Paulo: Martins Fontes. 
Foucault, M. (2011). O Nascimento da Clínica. Rio de janeiro: Forense Universitária.

Habinek, J. (2010). State-Building and the Origins of Disciplinary Specialization in Nineteenth-Century Germany. American Sociological Association Annual Conference, Atlanta-GA. https://www. researchgate.net/ publication/228785339_State-building_and_the_Origins_ of_Disciplinary_ Specialization_in_Nineteenth_Century_Germany

Mirabeau, H-G de R., Comte de (1791). Travail sur l'éducation publique, trouvé dans les papiers de Mirabeau l'aîné. Paris: l'Imprimerie nationale. http://gallica.bnf.fr/ark:/12148/bpt6k48974r

Pouliquen, Y. (2013). Cabanis, un idéologue de Mirabeau à Bonaparte. Paris: Odile Jacob.

Rey, R. (1993). L'Ecole de santé de Paris sous la Révolution: transformation et innovation. Histoire de l'Education , 57, 23-57.

Rosen, G. (1946). The Philosophy of Ideology and the Emergence of Modern Medicine in France. Bulletin of the History of Medicine,20, 328-339.

Saad, M. (2016). Cabanis, comprendre l'homme pour changer le monde. Paris: Garnier.

Staum, M. (1980). Cabanis: Enlightenment and Medical Philosophy in the French Revolution. Princeton: Princeton University Press.

Sousa-Santos, B., Almeida-Filho, N. (2008). A Universidade no século XXI: para uma universidade nova. Coimbra: Almedina.

Verneuil, I. (2013). L'école et la laïcité, de l'Ancien Régime à nos jours: enjeux du passé, enjeux dépassés ? Tréma (Dossier: Laicité, éducations, diversité) 31, 130-143.

Weisz, G. (2006). Divide and Conquer: A Comparative History of Medical Specialization. Oxford: Oxford University Press.

Williams, E. (1994). The Physical and the Moral: Anthropology, Physiology, and Philosophical Medicine in France, 1750-1850. Cambridge: Cambridge University Press.

\author{
Naomar Almeida-Filho \\ Instituto de Saúde Coletiva \\ Universidade Federal da Bahia - Campus Canela \\ E-mail: naomaralmeida@gmail.com
}

Correspondência:

Naomar Almeida-Filho

Instituto de Saúde Coletiva

Universidade Federal da Bahia - Campus Canela

Rua Basílio da Gama, s/n - Salvador-Bahia, Brasil

CEP: 40110-040

Data de submissão: Setembro 2017

Data de avaliação: Outubro 2017

Data de publicação: Março 2018 